\title{
Attitude survey in the ESG investment fund market $^{2}$
}

\section{Abstract}

Nowadays the so-called ESG investment funds are becoming increasingly popular in the world. There was a huge increase in the number of sustainable funds managed in Hungary too in 2020, so in the present paper I will examine the attitude of the Hungarian population toward this financial instrument. My goal is to explore the main obstacles and the potential drivers in the development of the market and to compare the results with relevant studies. I will use a decision tree and hierarchical clustering algorithms in order to find the characteristics of the target market. As a result, I will shed light on the fact that the main restraining factors are the lack of information and recommendations from financial providers. According to my research Hungarians are sensitive to environmental factors and the good performance of ESG funds compared to traditional ones can be an important aspect in their investment decisions. In defining the target group, the individual's demographics proved to be less influential, rather the basic attitude and perceptions toward ESG investments are the important factors.

Keywords: ESG, sustainability, investments, attitude survey

\section{Introduction}

Acting ethically in our finances is very important nowadays, and such a standpoint is becoming increasingly popular in the world. We can find so-called ESG funds in the portfolio of many fund managers these days, which take into account environmental,

1 Graduate student (MSc) of the Faculty of Finance and Accountancy of Budapest Business School in 2021; e-mail: reka.garamvolgyi2@gmail.com

DOI: http://dx.doi.org/10.31570/Prosp 20211

2 The present study is based on my master's thesis entitled "Attitude Survey in the ESG Investment Fund Market" presented in December 2020 at the Faculty of Finance and Accountancy of Budapest Business School. 
social and governance aspects in their designing phase. ESG investments are characterized by the inclusion of the three components of the acronym as separate factors in the analysis phase of investments, the aim of which is not primarily to undertake a mission but to improve the performance of the portfolio. Thus, according to the ESG philosophy, non-financial factors can also contribute to a company's profitability.

Ethical investment funds have raised several questions among researchers. Traditional portfolio theories generally assume rational investors and decisions in their models, so the fact that rationality is pushed into the background by ethical considerations suggests that the performance of portfolios so formed is not optimal according to traditional interpretations. As a result, many studies have been conducted to demonstrate that the inclusion of ESG factors in the model does not result in a loss of yield (Nakai et al. 2016; Jain et al. 2019; Lee et al. 2020). Some studies have however sought to find a link between financial profitability and ESG factors (Friede et al. 2015).

One of the most interesting areas of research on the topic is attitude survey, through which researchers sought to demonstrate factors that play a major role in investing in ESG funds (de Zwaan et al. 2015; Formankova et al. 2018; Wins et al. 2014). Based on the methods and results of the research, I conducted an attitude survey among the Hungarian population to examine the prejudices related to ESG investments, the driving forces, and the biggest obstacles to the development of this market.

\section{Research methodology}

Studying the questions of attitude surveys abroad, I conducted an online survey among the Hungarian population, using the so-called snowball method. The questions posed helped me to answer my four main research questions:

1. What are the main obstacles to the development of the Hungarian ESG market?

2. What factors may enhance development?

3. What are the characteristics of a potential customer base?

4. What are the prejudices of the Hungarian population regarding ESG funds?

Following data collection, I divided the sample into three main groups: (1) Investors, (2) Interested parties, (3) Non-interested parties. The Investors group consists of respondents who answered yes to the question of whether they have already invested in ESG funds. The Interested group includes those who, although have not heard of ESG funds previously, still indicated that they would be interested in them. In the Non- 
Interested group, I included those who, have heard about the investment, but did not choose it, and also those who have not heard about ESG funds and indicated that they were not interested in the instrument.

To measure sustainability attitudes (in line with the work of Wins et al. [2014]), I asked respondents two sets of questions: PSA ("Pro-social attitudes") is used to measure how favourably an individual acts in their daily lives in terms of social benefit, while PCE ("Perceived consumer effectiveness") shows the extent to which an individual believes in that he or she can contribute to solving social, environmental, and ethical problems through their actions.

To establish the PSA and PCE indicators, I asked 3 questions each, one concerning the environment, one society, and one corporate governance in case of both factors. Thus, I was able to examine sensitivity according to each factor separately. The answers to the questions were measured with a 5-point Likert scale, the scores of which were averaged to obtain the individual's PSA and PCE values.

To explore the variables that plaid an important role in which of the groups (Investor, Interested, Not Interested) an individual was included, I used the decision tree method, which confirms the hypothesis and helps to set up a model that can select a potential ESG customer based on individual characteristics.

Finally, I performed a cluster analysis on the sample in order to study the characteristics of the formed homogeneous groups and the extent to which they correspond to the formed Investor-Interested-Non-Interested groups.

\section{Research results}

As described above, I collected the population sample needed to answer the research questions using an online questionnaire. The questionnaire was completed by 141 people, however, in order for the sample to be representative from a population point of view, I performed weighting based on the distributions according to the actual population age groups. I excluded the under-18 age group from the analysis because most of them do not yet have their own savings yet and therefore I did not consider them relevant to the study. The weights and modified distributions are shown in Table 1, where I calculated the population ratios from the estimated data of the CSO in 2020 (CSO 2020). 
Table 1: Distributions by age groups weighted by population ratios

\begin{tabular}{|c|c|c|c|c|c|c|c|}
\hline & \multicolumn{2}{|c|}{ Population } & \multicolumn{2}{c|}{ Sample } & \multicolumn{3}{c}{ Modified } \\
\hline & $N$ & ratio & N & ratio & weigh. & N & ratio \\
\hline $\mathbf{1 8 - 2 5}$ & $\mathbf{8 6 3 6 9 9}$ & $11 \%$ & 58 & $42 \%$ & $25 \%$ & 15 & $11 \%$ \\
\hline $\mathbf{2 6 - 3 5}$ & 1248451 & $15 \%$ & 38 & $28 \%$ & $56 \%$ & 21 & $15 \%$ \\
\hline $\mathbf{3 6 - 4 5}$ & 1369654 & $17 \%$ & 16 & $12 \%$ & $147 \%$ & 23 & $17 \%$ \\
\hline over 45 & 4578674 & $57 \%$ & 26 & $19 \%$ & $301 \%$ & 78 & $57 \%$ \\
\hline Total & $\mathbf{8 0 6 0 4 7 8}$ & & $\mathbf{1 3 8}$ & & & $\mathbf{1 3 8}$ & \\
\hline
\end{tabular}

Source: Table by author

Based on the answers to the questions, three groups were formed: $4.5 \%$ investors, $32.3 \%$ interested and $63.2 \%$ non-interested.

\section{Demographic hypotheses}

First, I looked for a link between age and the group in which the respondents were categorised. The independence test used to reveal such a relationship did not show a significant connection between the two variables (Cramer V=0.108, $p=0.781$ ). According to my hypothesis, the millennial generation (18-25) is more socially sensitive, which is why there is a significant difference in their attitudes as opposed to other age groups.

Table 2: PSA and PCE scores for each age group

\begin{tabular}{|l|c|c|c|c|c|c|}
\hline & \multicolumn{3}{|c|}{ PSA } & \multicolumn{3}{c}{ PCE } \\
\hline & Mean & Median & Mode & Mean & Median & Mode \\
\hline $\mathbf{1 8 - 2 5}$ & 3,91 & 4,00 & 4,00 & 4,22 & 4,33 & 4,33 \\
\hline $\mathbf{2 6 - 3 5}$ & 3,26 & 3,67 & 4,00 & 4,04 & 4,33 & 4,33 \\
\hline $\mathbf{3 6 - 4 5}$ & 3,88 & 4,00 & 4,00 & 4,13 & 4,17 & 4,00 \\
\hline Over 45 & 4,09 & 4,00 & 4,00 & 4,22 & 4,33 & 4,00 \\
\hline
\end{tabular}

Source: Table by author

To verify the data, I performed variance analysis with the PSA and PCE measures. The condition of the variance analysis was met in the case of the PCE index, and according to the analysis, the average scores of the age groups can be considered the same 
at a significance level of $5 \%(p=0.632)$. However, in the case of PSA, the precondition was not met, so I examined the results of the Tamhane T2 test. Based on these, at the $5 \%$ significance level, it can be seen that the 26-35 age group differs significantly from the over 45 age group in terms of their social attitudes, namely their average scores are lower (see Table 2), however, the attitudes of the examined 18-25 age group cannot be considered significantly different, so I rejected my hypothesis.

Based on previous research, my assumption about the genders was that women are more interested in the topic of ESG than men. The performed independence test did not support this, as there was no detectable relationship between group categorization and gender at the 5\% significance level. I then examined their attitudes, as shown in Table 3.

Table 3: Mean scores of attitudes of men and women and results of $t$-tests

\begin{tabular}{c|c|c|c|c|c|c}
\hline \multirow{2}{*}{ Mean } & PSA & PCE & $\begin{array}{c}\text { Environmental } \\
\text { sensitivity }\end{array}$ & $\begin{array}{c}\text { Social } \\
\text { sensitivity }\end{array}$ & $\begin{array}{c}\text { Governance } \\
\text { sensitivity }\end{array}$ \\
\cline { 2 - 7 } & Men & 4,11 & 4,20 & 4,36 & 4,04 & 4,05 \\
\hline \multirow{2}{*}{ t-test } & p value & 0,003 & 4,15 & 4,01 & 3,78 & 3,91 \\
\hline
\end{tabular}

Source: Table by author

While the mean scores of men and women in terms of perceived consumer usefulness can be considered the same, they proved to be significantly different in social attitudes, as the mean scores of women were significantly higher. In order to find out whether there is a gender difference in sensitivity to environmental, social, and governance factors, I combined the E, S, and G-oriented questions of PSA and PCE rates, thus creating three new variables from the mean scores. T-tests revealed that at the $5 \%$ significance level in factor $\mathrm{E}$ and at the $10 \%$ significance level in factor $\mathrm{S}$ the mean scores of men and women can be considered different (both are significantly higher for women), while their sensitivity to factor $\mathrm{G}$ can be considered the same.

My hypothesis concerning the relationship between education and ESG potential was that interest in ESG increases with educational attainment. The two variables can also be considered ordinal, so in addition to the Cramer index, I also examined the Gamma and the Kendall tau-c measures as part of the independence test. 
Nominal measures did not show a relationship between the two criteria; however, the ordinals indicated a weak relationship at the 5\% significance level (Gamma $=0.413$, Kendall tau-c $=0.139$ ). Although the interest rate appears to be higher among those with higher educational qualifications (36.2\%) than among those with lower educational attainment (19.2\%), I could not fully accept my hypothesis due to the closeness of the relationship.

I also considered the place of residence to be a potential influencing factor, because in big cities, due to the more polluted air and social problems, people's interest in sustainable products may be stronger. However, I had to refute my hypothesis as the independence test did not show a significant relationship between group category and residence ( $p=0.152$, Cramer $\mathrm{V}=0.185$ ). Based on the variance analysis according to the PSA and PCE values, I did not find any category that differed significantly from the others in their attitudes, and there was no trend pointing in such a direction that could be established from the mean scores of the groups.

Table 4: PSA and PCE mean scores for each residence type

\begin{tabular}{c|c|c|c|c|c|c|c|}
\hline \multicolumn{3}{|c|}{ PSA } & \multicolumn{4}{c|}{ PCE } \\
\hline Village & Town & County seat & Capital & Village & Town & County seat & Capital \\
\hline 4,55 & 3,72 & 4,06 & 3,72 & 4,33 & 4,16 & 4,23 & 4,09 \\
\hline
\end{tabular}

Source: Table by author

In summary of my demographic hypotheses, it can be said that demographic characteristics do not have much influence on the interest in ESG investments. At the same time, educational attainment proved to be a significant variable and in terms of environmental and social issues agreement was not absolute between men and women.

\section{Hypotheses concerning investment decisions}

Demographic factors did not prove decisive in terms of interest in ESG investments, however, it was important to examine what are the criteria that have an influence on investment decisions, so I could get closer to defining the consumer category of ESG funds. I assumed that financial literacy and risk appetite may be crucial aspects in the choice. In addition, examining the decision-making process was also worthwhile, as 
those who may prioritize ESG considerations in the selection process may seem promising customers.

Variance analysis of the variables of risk appetite and financial literacy showed that the mean scores of the three interest groups could be considered the same (risk-taking: $p=0.572$, financial literacy: $p=0.749$ ), so these variables did not significantly affect the probability of joining one group or another.

Table 5: Mean scores of groups according to financial literacy and risk appetite

\begin{tabular}{|c|c|c|c|c|c|}
\hline \multicolumn{3}{|c|}{ Risk appetite } & \multicolumn{3}{c|}{ Financial literacy } \\
\hline Not interested & Interested & Investor & Not interested & Interested & Investor \\
\hline 2,82 & 2,66 & 2,97 & 3,27 & $3, r 41$ & 3,20 \\
\hline
\end{tabular}

Source: Table by author

46.4\% of respondents considered return to be the most important in investment decision making. This was in line with my preliminary assumptions. ESG factors in decision making most often ranked only 4 th out of the five factors ${ }^{3}$ (among $48.6 \%$ of the respondents). The relationship between the order of ESG aspects and the groups was not supported by the variance analysis, as there was no significant difference among the group means $(p=0.467)$.

Then, based on my assumptions, I created a variable that classifies into separate categories those who ranked ESG aspects ahead of return and those who did not. Although the independence test showed almost no relationship between the group and the created variable, on examining the attitudes, I found significant differences. The mean scores $(p=0.001)$ of the two established groups cannot be considered the same in case of the PSA and PCE indicators either, as the attitudes of those who rank the ESG aspects before the return are significantly stronger.

3 The factors given were: return, risk, liquidity, product simplicity and ESG considerations. 
Table 6: Mean PSA and PCE scores and proportions of those who ranked ESG ahead of return compared to those who ranked return ahead

\begin{tabular}{c|c|c|c|c|}
\hline \multirow{2}{*}{} & \multicolumn{2}{|c|}{ PSA } & \multicolumn{2}{c|}{ PCE } \\
\hline & $\begin{array}{c}\text { Return more } \\
\text { important }\end{array}$ & $\begin{array}{c}\text { ESG more } \\
\text { important }\end{array}$ & $\begin{array}{c}\text { Return more } \\
\text { important }\end{array}$ & $\begin{array}{c}\text { ESG more } \\
\text { important }\end{array}$ \\
\hline Mean score & 3,81 & 4,52 & 4,11 & 4,59 \\
\hline Distribution in sample & $86 \%$ & $14 \%$ & $86 \%$ & $14 \%$ \\
\hline
\end{tabular}

Source: Table by author

\section{Hypotheses concerning sustainability attitudes}

I have already examined the sustainability attitudes of the respondents in part when testing the previous hypotheses. Further analysis was required to establish PSA and PCE values for the three interest groups. After examining the scores, it turned out that the social attitudes of the Interested Group were the strongest, while in terms of perceived consumer utility, the Investors received the highest mean scores (see Table 7). However, based on the variance analysis, the means of the indicators were found to be the same in the groups.

Table 7: The PSA és PCE scores of the groups

\begin{tabular}{c|c|c|c|c|c|c}
\hline & \multicolumn{3}{|c|}{ PSA } & \multicolumn{3}{c}{ PCE } \\
\hline & Mean & Median & Mode & Mean & Median & Mode \\
\hline $\begin{array}{c}\text { Not } \\
\text { Interested }\end{array}$ & 3,88 & 4,00 & 4,00 & 4,13 & 4,00 & 4,00 \\
\hline Interested & 4,03 & 4,00 & 4,00 & 4,23 & 4,33 & 4,67 \\
\hline Investor & 3,40 & 3,67 & 4,00 & 4,36 & 4,33 & 4,33 \\
\hline
\end{tabular}

Source: Table by author

A German attitude survey showed that different groups of investors interpret the concept of sustainability differently, as those who are interested or investing in ESG funds interpret the concept broadly and include more factors in it than those who are not interested in this form of investment (Wins et al. 2014). 
Table 8: The groups' associations with the concept of sustainability

(compared to the results of Wins et al. 2014)

\begin{tabular}{c|c|c|c}
\hline & Not Interested & Interested & Investor \\
\hline \multirow{2}{*}{ Environment } & $\begin{array}{c}61,6 \% \\
(18,4 \%)\end{array}$ & $\begin{array}{c}47,9 \% \\
(16,4 \%)\end{array}$ & $\begin{array}{c}42,0 \% \\
(3,4 \%)\end{array}$ \\
\hline \multirow{2}{*}{ Ethical } & $0,6 \%$ & $1,3 \%$ & $0,0 \%$ \\
behaviour & $(3,2 \%)$ & $(3,6 \%)$ & $(0,0 \%)$ \\
\hline \multirow{2}{*}{ Economy } & $14,0 \%$ & $2,4 \%$ & $9,1 \%$ \\
\hline \multirow{2}{*}{ Society } & $(19,5 \%)$ & $(9,1 \%)$ & $(6,9 \%)$ \\
\hline \multirow{2}{*}{ All } & $0,6 \%$ & $0,6 \%$ & $0,0 \%$ \\
& $(1,1 \%)$ & $(3,0 \%)$ & $(1,7 \%)$ \\
\hline \multirow{2}{*}{ Non } & $23,1 \%$ & $41,1 \%$ & $48,9 \%$ \\
& $(42,1 \%)$ & $(66,7 \%)$ & $(86,2 \%)$ \\
\hline \multirow{2}{*}{ Total } & $0,0 \%$ & $6,8 \%$ & $0,0 \%$ \\
& $(15,8 \%)$ & $(1,2 \%)$ & $(1,7 \%)$ \\
\hline
\end{tabular}

Source: Author's research and Wins et al. (2014)

I compared the ratios obtained from my own research with the 2014 study by Wins et al. (see Table 8.) and found that although the assumption that those who are more receptive to ESG interpret the definition of sustainability more broadly seems to be correct, the German sample showed a much higher proportion of "All" responses, while the Hungarian sample indicated a difference mainly in environmental factors.

In summary it can be stated that the hypotheses regarding sustainability attitudes confirmed the preliminary assumption that most of the respondents will think of the environment with reference to sustainability associations. Examining the PSA and PCE means of the interest groups, I concluded that the mean scores are not proportional to the degree of involvement in ESG investments.

\section{Hypotheses concerning ESG investment biases}

After surveying the respondents 'investment and sustainability attitudes, I researched their biases and basic attitudes towards ESG investments. I this respect it is important to know how each group perceives return and risk, and whether they would be willing 
to make a sacrifice on returns in order to put their money into an investment that is responsible in some ways.

After conducting an independence test, I concluded that being in one group or another does not significantly depend on their biases concerning risk, but it can slightly influence how they feel about the return on ESG investments compared to traditional ones.

Table 9: The result of an independence test between the group and return and risk perception

\begin{tabular}{l|c|c|c|c}
\hline & \multicolumn{2}{|c|}{ Return perception } & \multicolumn{2}{c}{ Risk perception } \\
\hline & Indicator value & $p$ value & Indicator value & $p$ value \\
\hline Phi & 0,287 & 0,023 & 0,192 & 0,276 \\
\hline Cramer V & 0,203 & 0,023 & 0,136 & 0,276 \\
\hline
\end{tabular}

Source: Table by author

The answers to the questions without being broken down by groups are shown in Table 10.

Table 10: Return perception and risk perception in the sample

\begin{tabular}{l|c|c}
\hline & $\begin{array}{c}\text { Do you think you can expect a } \\
\text { lower return if you invest your } \\
\text { money sustainably? }\end{array}$ & $\begin{array}{c}\text { Do you think sustainable } \\
\text { investments carry a higher risk? }\end{array}$ \\
\hline Yes & Distribution & Distribution \\
\hline No & $28,7 \%$ & $17,5 \%$ \\
\hline Don't know & $48,1 \%$ & $56,7 \%$ \\
\hline
\end{tabular}

Source: Table by author

Nearly half of respondents believe that sustainable investments do not yield lower returns, but it is very interesting that $28.7 \%$ say it is a less profitable investment. Slightly less - $17.5 \%$ - responded that ESG investments were riskier than their traditional counterparts. My hypothesis in this regard was that in the case of both return and risk, there will be a higher proportion of those who associate them with lower return and/or higher risk, however on the basis of the results I had to reject my hypothesis. 
In Table $11 \mathrm{I}$ compared in each sustainability factor the proportion of the returns respondents were willing to sacrifice in order to make them sustainable.

Table 11: Willingness to sacrifice according to different ESG aspects

\begin{tabular}{|l|c|c|c|}
\hline & Environmental & Social & Governance \\
\hline Yes & $45,4 \%$ & $37,4 \%$ & $33,7 \%$ \\
\hline No & $18,3 \%$ & $20,4 \%$ & $19,4 \%$ \\
\hline May be & $36,3 \%$ & $42,2 \%$ & $46,9 \%$ \\
\hline
\end{tabular}

Source: Table by author

Most respondents would make sacrifices for the sake of the environment, which is perhaps not so surprising in light of what we have seen with respect to the issue of sustainability associations. What is interesting, however, is the low the proportion of those who would reject sacrifice from the start.

I also tested the willingness to sacrifice in each group, as shown in Table 12.

Table 12: Result of an independence test between willingness to sacrifice and group

\begin{tabular}{l|c|c|c|c|c}
\hline & & & \multicolumn{3}{c}{ Ratio of "Yes" responses } \\
\hline & Cramer V value & $p$ value & Not interested & Interested & Investor \\
\hline Environmental & 0,259 & 0,001 & $41,0 \%$ & $57,9 \%$ & $18,2 \%$ \\
\hline Social & 0,310 & 0,000 & $24,7 \%$ & $65,1 \%$ & $18,2 \%$ \\
\hline Governance & 0,262 & 0,001 & $25,8 \%$ & $51,4 \%$ & $18,2 \%$ \\
\hline
\end{tabular}

Source: Table by author

I found a significant relationship between group categorization and willingness to sacrifice in case of each ESG factors, although this relationship proved to be weak. The ratio of "yes" responses is significantly higher in the Interested group than in the Not interested group. So far, this variable has the greatest impact on group categorization.

The focus then shifted to uncovering motivations. $22.9 \%$ of the respondents have already heard of ESG funds. Of those who have not heard of this type of investment, $42 \%$ are interested in it. Those who have already invested in or are interested in an ESG fund 
had to say why they chose/would choose this investment. According to my preliminary assumptions, environmental considerations will be the most common reason in both groups. Chart 1. shows the distribution of the respondents by factors.

Figure 1: Occurrence rate of the motivations of investor and those interested among respondents

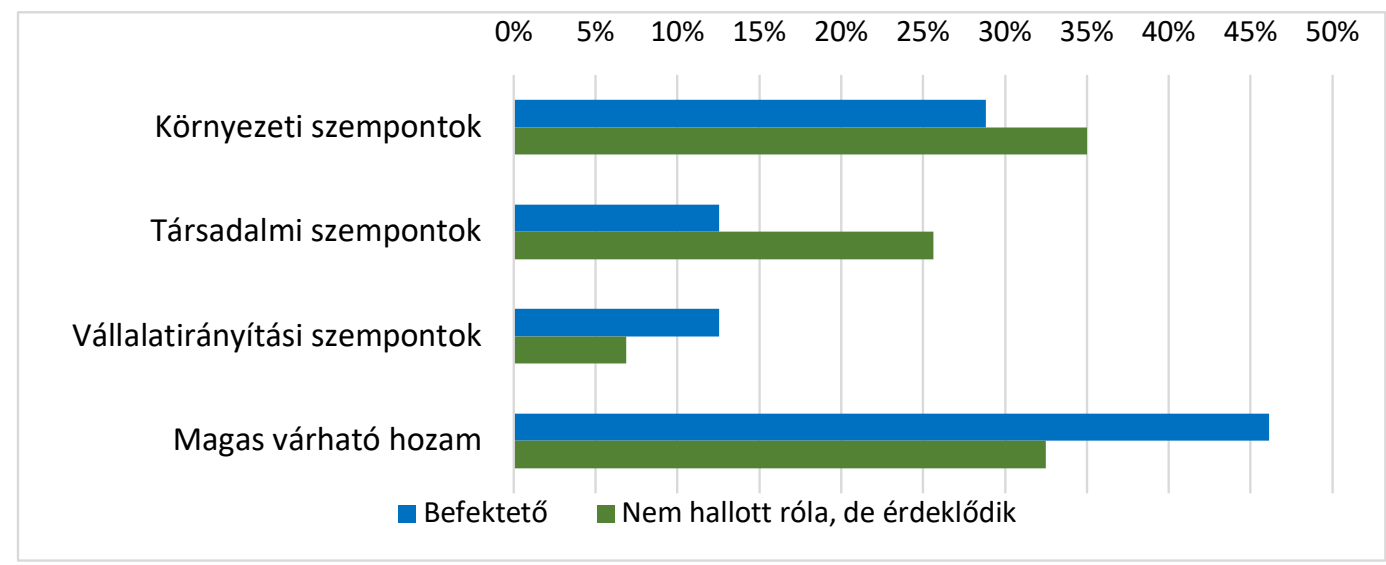

\section{Source: Chart by author}

It appears from the responses that the most common motivation among Investors was high returns, so I rejected my hypothesis, still $29 \%$ of them also took into account environmental considerations. In the case of the Interested Group, however, the hypothesis was confirmed, as the most common motivation here would indeed be the environmental aspect.

Based on previous research, my hypothesis was that the reason for those who have heard of it but still have not invested in an ESG fund is mainly that they expect a lower return than from traditional investments, while the reason for those who have not heard of it and are not interested in it is mainly lack of information. Distribution of respondents according to the various reasons is shown in Chart 2.

As you can see the most common reason in both groups under study was the lack of information, but this number was much higher among those who had not heard of the product at all, as more than half of the respondents chose this option. The second most common reason was that no one recommended this product to them. Only $11 \%$ of the respondents identified a lower return as a reason among those who had heard of it, so I rejected this hypothesis, but accepted the one for the other group. 
Figure 2: Occurrence rate of reasons in the case of respondents not investing or not interested in ESG funds

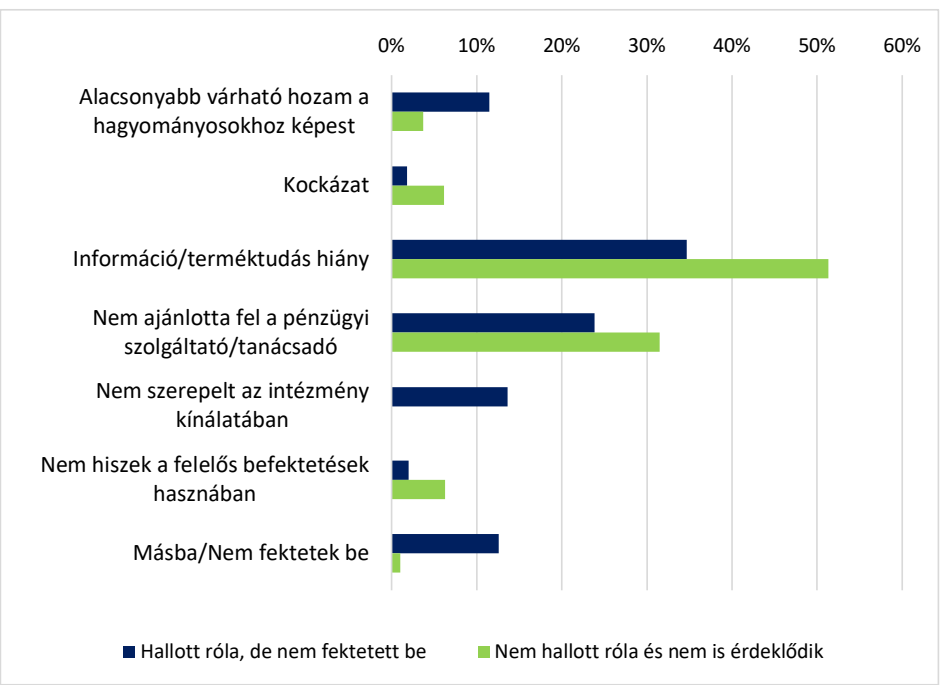

Source: Chart by author

\section{Decision tree}

To support my hypothesis, I chose another method, the decision tree. My goal was to define the classification rule by which the respondents could be categorised into their respective groups.

I used the CHAID method because the variable to be estimated is not a continuous but a category variable. The inputs to the model are: demographic characteristics, risk appetite, financial literacy, return perception, risk perception, order of consideration of ESG aspects, willingness to sacrifice by each ESG factor, and PSA and PCE values.

In their 2014 research, Wins et.all also included similar variables in their decision tree model and made a $65.6 \%$ accuracy forecast for three investor groups. The similarity between investors and interested parties was too great, so in the second model they combined the two groups (using the "available" category), thus increasing the accuracy of the model to $74.6 \%$. The key variables involved in the classification were, in hierarchical order: the importance of taking into account sustainability considerations, PCE, ESG conceptual knowledge, and PSA.

In the preliminary phase of setting up the decision tree, I also combined the investor and the interested groups, mainly due to the fact that there were too few people in the investor groups. The results are illustrated by the tree structure generated by the SPSS program. 
Figure 3.: Decision-tree with two categories

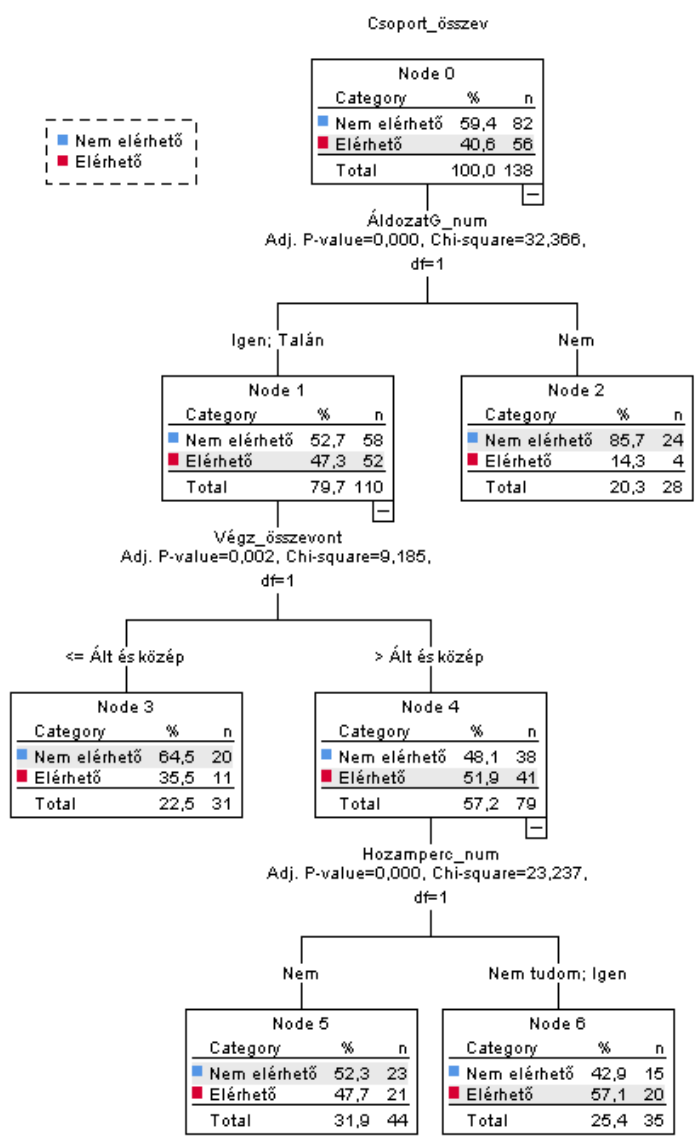

Source: Edited by the author in SPSS program

The accuracy of the model thus obtained was $63 \%$. The category of those not accessible was predicted by $81.7 \%$ precision, while the model was able to predict the category of those accessible only by $35.7 \%$. The variables involved were willingness to sacrifice based on governance aspects, educational attainment, and performance biases.

The decision-tree was consistent with my preliminary expectations and the result of the hypothesis testing, except for the return perception criterion. According to the classification rule, those who say that ESG investments do not yield lower returns than traditional ones are less likely to be approachable than those who say ESG funds have lower returns or those who say they do not know. This suggests a minor discrepancy between perceptions and behaviour and would require further study. 
In conclusion I must say that the reliability of the model is not convincing, however, the Not-Interested group appears to be more distinct and predictable than the Interested group.

\section{Cluster analysis}

Since neither the hypothesis testing nor the decision tree method provided a clear set of rules by which to delimit attitudes towards ESG funds, I wanted to see what homogeneous groups could be produced from the sample and how they could be characterized. The most suitable method for this is hierarchical cluster analysis.

The input variables were the investment and sustainability attitudes used in the decision tree model, but I did not include the demographic characteristics, as I will use their mean values to characterize the clusters. I compared the received clusters with the actual groups to see which group they correspond to and what the reasons for the differences might be.

For reasons of comparability, I studied both a three- and a two-cluster model. I wished to minimize the average distance among the elements within the group for which I chose the squared Euclidean distance. I compared the obtained clusters with the mean values according to the criteria involved and the demographic characteristics.

Table 13: Mean scores of the attitudes in the three-cluster model ${ }^{4}$

\begin{tabular}{|c|c|c|c|c|c|c|c|c|c|c|c|}
\hline & $z$ & 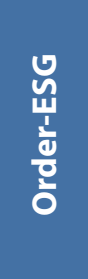 & 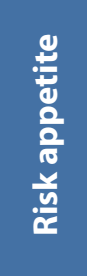 & 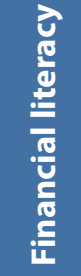 & 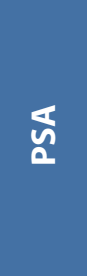 & ய & 돟 $\frac{\text { 을 }}{\frac{3}{0}}$ & $\begin{array}{l}\frac{5}{0} \\
\frac{0}{0} \\
\frac{0}{y} \\
\frac{0}{0} \\
\frac{y}{\alpha}\end{array}$ & 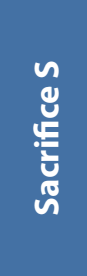 & 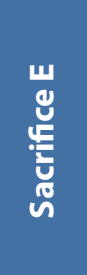 & 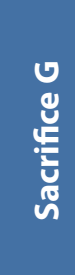 \\
\hline 1 & 56 & 3,13 & 3,05 & 3,45 & 4,11 & 4,39 & 2,39 & 2,23 & 2,80 & 2,88 & 2,75 \\
\hline 2 & 8 & 1,38 & 4,13 & 4,00 & 1,33 & 3,96 & 2,50 & 2,88 & 1,25 & 1,25 & 1,25 \\
\hline 3 & 74 & 2,03 & 2,45 & 3,04 & 3,76 & 4,01 & 2,16 & 2,23 & 1,81 & 1,93 & 1,86 \\
\hline
\end{tabular}

Source: Table by author

4 The first five variables in the table move on a scale of 5, while the second five variables move on a scale of 3 . The higher the values for sustainability attitudes, the better the group's attitude towards ESG, while the higher risk appetite and financial literacy values refer to higher risk appetite and higher financial literacy. 
We can observe that when creating three clusters the number of those in the second cluster is very low, so it was better to use two clusters and analyse those more thoroughly.

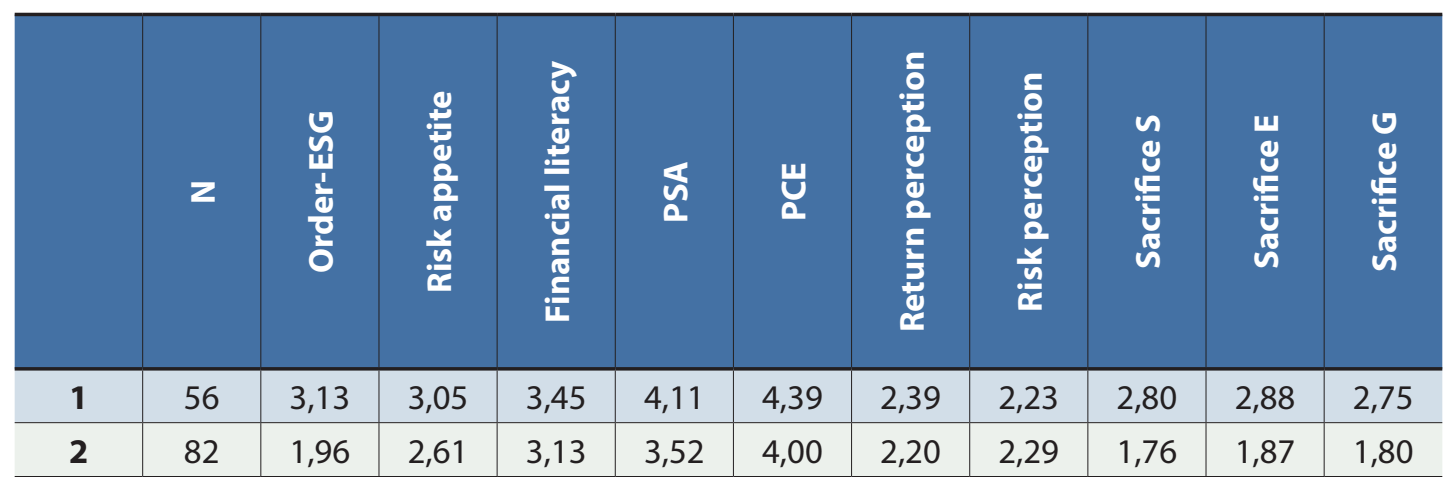

Source: Table by author

As you can see the former 8-person cluster merged into the second cluster, so based on their characteristics, they can be described as an inaccessible category for ESG, while the first cluster constitutes the accessible category as their attitudes towards sustainability are significantly higher. The first cluster is mostly made up of women whose average age is lower than that of the second group, they have a higher mean score for educational attainment and they mainly live in big cities. I compared my assumption with the actual groups and the results coincide, as $67 \%$ of those not accessible were in the second cluster, while $51 \%$ of those accessible were in the first. I will attempt to answer the reasons for the differences between the actual groups and the clusters in my conclusion.

\section{Conclusion}

I have performed a comprehensive analysis of a Hungarian population sample in order to answer my research questions. The questions were aimed at finding out the characteristics of the potential client base of ESG funds, the setbacks in the ESG fund market,

5 The first five variables in the table move on a scale of 5, while the second five variables move on a scale of 3 . The higher the values for sustainability attitudes, the better the group's attitude towards ESG, while the higher risk appetite and financial literacy values refer to higher risk appetite and higher financial literacy. 
the possible drivers of development and the biases of the people towards this form of investment.

Overall, I concluded that demographic considerations did not play a significant role in whether someone was interested in this form of investment or not, and although educational attainment came up in the decision tree as a cutting point, I found only a weak relationship when I performed a hypothesis test. Financial literacy, risk appetite, and the order of factors involved in the investment decision process seemed to be important considerations before the analysis, however, results show that although in many cases there is a difference in attitudes, this is not coupled with actual interest.

This phenomenon is called attitude-behaviour gap in the literature. It has been discovered by many researchers that a consumer with a high sustainability attitude does not necessarily act according to his or her attitudes when making real-life purchasing decisions. There are two basic explanations for this phenomenon. According to one, the reason for the gap is the use of questionnaires, as this is tool that is applied mainly in the assessment of attitudes. A respondent may give socially more acceptable answers to the questions instead of his/her real opinion and habits, and thus the reality content of the result is distorted. The other explanation suggests that a number of external factors may distract the consumer from a purchase based on his or her attitudes (Schäufele et al. 2018).

A study on German investors concluded that doubt in returns seems to be one of the major obstacles, while among Hungarians it is the lack of knowledge. What played a part in the decision of those who would not or have not chosen this type of investment was mainly lack of information or lack of an offer. Based on my research, I my opinion these two factors can be considered the greatest setbacks.

ESG investments have only recently appear in the Hungarian market, and in 2020 there was a sharp increase in the number of these funds (Bamos 2020). This supply expansion should be supported by finding demand in a targeted way. Counsellors play a highly important role in this.

I have concluded from my research, that the Hungarian population is the most sensitive to environmental aspects, so in the development of the market, this aspect of the ESG funds should be the highlighted the most. However, when I studied the investors, it was not necessarily their interest in sustainability that led to the actual investment, but high returns also played a major role. This factor can also be used in the development of the market. 
To sum up the lesson that can be learnt from the attitude study is that there is possibility to expand the ESG market. If market participants can solve the problems of lack of information and lack of offers, by highlighting the responsible, green element of the investment an increasing amount of customer asset may be invested in ESG type instruments.

\section{References}

BAMOSZ (Association of Hungarian Investment Fund and Asset Management Companies) (2020). Downloads, Downloaded: 28. 09. 2020., Retrieved from: http:// www.bamosz.hu/letoltesek

de Zwaan, L. - Brimble, M. - Stewart, J. (2015). Member perceptions of ESG investing through superannuation. Sustainability Accounting, Management and Policy Journal, 6(1), 79-102. https://doi.org/10.1108/SAMPJ-03-2014-0017

Formankova, S. -Trenz, O. - Faldik, O. - Kolomaznik, J. - Vanek, P. (2018). The future of investing-sustainable and responsible investing. Marketing and Management of Innovations, 2, 94-102. http://doi.org/10.21272/mmi.2018.2-08

Friede, G. - Busch, T. - Bassen, A. (2015). ESG and financial performance: aggregated evidence from more than 2000 empirical studies, Journal of Sustainable Finance \& Investment, 5(4), 210-233. https://doi.org/10.1080/20430795.2015.1118917

Jain, M. - Sharma, G. D. - Srivastava, M. (2019). Can Sustainable Investment Yield Better Financial Returns: A Comparative Study of ESG Indices and MSCI Indices. Risks, 7(1), 15. https://doi.org/10.3390/risks7010015

KSH (HCSO) (2020). Népesség korév és nem szerint. (Population by age and gender.) Downloaded: 16. 11. 2020. Retrieved from: https://www.ksh.hu/docs/hun/xstadat/ xstadat eves/i wdsd009.html

Lee, D. D. - Fan, J. H. - Wong, V. S. H. (2020). No More Excuses! Performance of ESG Integrated Portfolios in Australia. Accounting \& Finance, forthcoming. https://doi. org/10.2139/ssrn.3128759

Nakai, M. - Yamaguchi, K. - Takeuchi, K. (2016). Can SRI Funds Better Resist Global Financial Crisis? Evidence from Japan. International Review of Financial Analysis, 48, 12-20. https://doi.org/10.1016/j.irfa.2016.09.002 
Schäufele, I. - Hamm, U. (2018). Organic wine purchase behaviour in Germany: Exploring the attitude-behaviour-gap with data from a household panel. Food Quality and Preference, 63, 1-11. https://doi.org/10.1016/j.foodqual.2017.07.010

Wins, A. - Zwergel, B. (2014). Comparing those who do, might and will not invest in sustainable funds: a survey among German retail fund investors. https://doi. org/10.2139/ssrn.2443721 